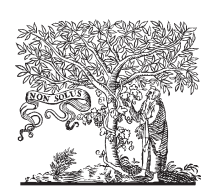

ELSEVIER

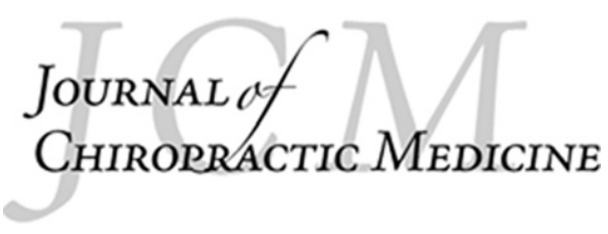

www.journalchiromed.com

\title{
Topics in Pediatrics
}

\section{Cellulitis of the Knee in a 16-Month-Old Boy: A Case Report}

\section{Sonia V. Joubert $D C^{a, *}$, Manuel A. Duarte $D C^{b}$}

${ }^{a}$ Chiropractic Physician, Attending Clinician, National University of Health Sciences, Lombard, IL

${ }^{\mathrm{b}}$ Chiropractic Physician, Chair of Clinical Practice, National University of Health Sciences, Lombard, IL

Received 12 September 2014; received in revised form 28 August 2015; accepted 8 September 2015

\section{Key indexing terms:}

Cellulitis;

Skin diseases;

Infectious;

Methicillin-resistant Staphylococcus aureus

\begin{abstract}
Objective: The purpose of this case report is to describe the presentation of cellulitis in a 16month-old boy to a chiropractic clinic.

Clinical Features: The patient presented with nontraumatic, sudden onset of nonpurulent erythema on the right knee. A plain film radiograph of the knee showed a 40-mm thickening of the anterior knee. A diagnosis of cellulitis was rendered based on the presentation of the rapidly spreading erythema and radiographically confirmed findings.

Intervention and Outcome: The patient was immediately referred to the local emergency room. The patient was hospitalized, treated with clindamycin and amoxicillin for 3 days, and then discharged. The patient's pediatrician discontinued clindamycin treatment at the posthospitalization follow-up. Two weeks after treatment was discontinued, the patient was diagnosed with recurrent cellulitis.

Conclusion: This case demonstrated that for this young patient with cellulitis of the knee, timely recognition and referral, together with patient or parent education and immediate treatment, were essential to a successful outcome.

(C) 2016 National University of Health Sciences.
\end{abstract}

\section{Introduction}

Cellulitis is an infection of the skin and subcutaneous tissues that can spread rapidly. It is clinically diagnosed based on the presentation of a nonpurulent erythemic rash with irregular margins, edema, and local tenderness. ${ }^{1-8}$

\footnotetext{
* Corresponding author at: Sonia V. Joubert, DC, $1055 \mathrm{~N}$ Farnsworth Ave, Aurora, IL, 60505.

E-mail address: sjoubert@nuhs.edu (S. V. Joubert).
}

The most common presentation for cellulitis of the lower extremities is a secondary condition due to trauma, which is most commonly seen in sports-related trauma or trauma involving foreign bodies. Other common presentations are seen among patients with a body mass index higher than 31 , geriatric patients, and patients with a history of diabetes or immune compromise. ${ }^{6,9-14}$

The presentation of cellulitis to a chiropractic clinic is not commonly reported in the literature. At present, only 1 case report exists which describes the 
presentation in an adolescent. ${ }^{5}$ Therefore, the purpose of this case report is to describe the presentation of cellulitis in a 16-month-old boy to a chiropractic clinic.

\section{Case Report}

An otherwise healthy 16-month-old boy presented to a chiropractic clinic with initial chief complaint of a "red, angry rash" on the right knee, as described by the patient's mother.

The patient's mother noticed the erythematous reaction during a diaper change on the morning of the visit but denied any noticeable erythematous rash, pyrexia, or skin markings on the day before the office visit.

The patient exhibited no signs of distress and no apparent guarding while walking. Patient's medical history revealed no allergies, no medication, and no changes in food or environment. It also included no recent hospitalizations, except when he was previously treated for an upper respiratory infection 4 months prior. He was treated with amoxicillin, and the infection was resolved with no exacerbations or complications.

The physical examination findings were as follows: vital signs: temperature, $98.6^{\circ} \mathrm{F}$; heart rate, 92 beats per minute; blood pressure, 90/64; Resp. 22 rmp other findings included the patient's right knee, which had a warm, nonpurulent erythema with an irregular border over the anterior aspect. There were visible striations of petechiae noted arising from the right knee, extending up into the posterior torso, but not crossing the spine. There were no signs of insect bites, scratches, or trauma noted on observation, and the knee was painful to palpation (Fig 1). The abdomen and all other areas of the body were inspected and examined, showing no erythema, palpatory tenderness, insect bites, or trauma.

During the initial consultation and examination of the patient, it was noted that there was a rapid change in presentation of symptoms that indicated a quickly spreading erythematous reaction. Considering the patient's age and presentation, cellulitis, streptococcal toxic shock syndrome, necrotizing fasciitis (NF), and methicillin-resistant Staphylococcus aureus (MRSA) were not diagnoses to be dismissed or disregarded. They all have similar initial presentation, and their outcome could vary from antibiotic treatment, surgical debridement, toxic shock, or death. ${ }^{9,10,15-18}$ Taking into consideration the fast progression of the erythematous reaction, irregular margins, striations, and nonpurulent presentation, the patient was diagnosed with

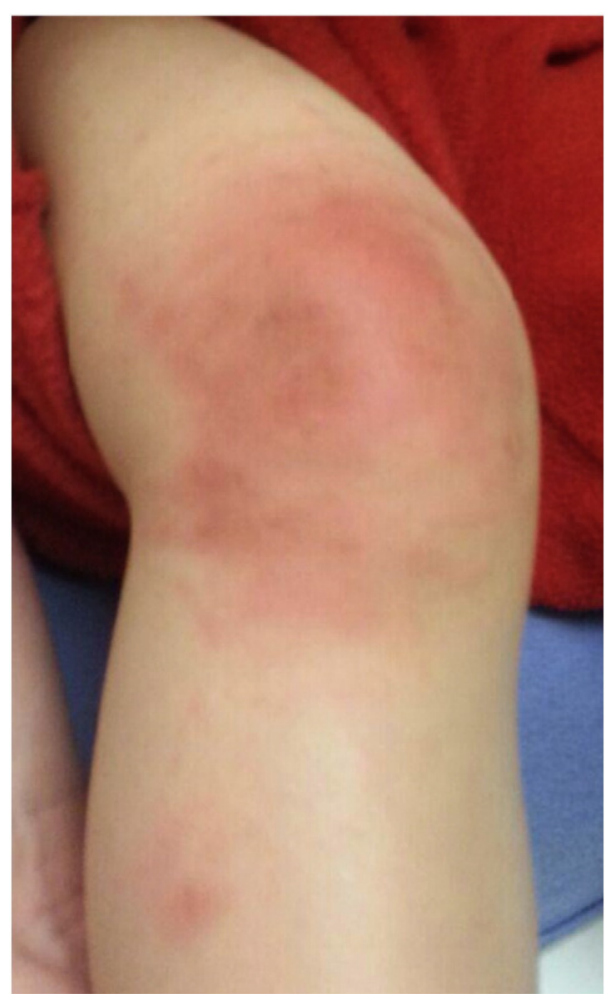

Fig 1. Patient's right knee at time of presentation to chiropractic clinic; arrow pointing to initial erythema presentation.

acute cellulitis. The importance of immediate care was explained to the parents, and the patient was referred to the local emergency department (ED).

Upon arrival to the ED, the patient's symptoms had progressed to warm nonpurulent erythema with irregular striations over the abdomen, torso, and bilateral knee. He was then diagnosed with viral exanthema and treated with Benadryl. The abdomen and left knee areas were not affected 1 hour before at the chiropractic clinic (Fig 2). Because of the presence of the additional erythema, the patient remained in the ED under observation until additional tests were performed.

Tests ordered at the hospital included complete blood count, microspecimen, and basic metabolic panel along with a plain film radiograph of the right knee. The results were indicative of the presence of an acute infection. The plain radiograph report of the right knee indicated a mild, nonspecific radioopaque stranding 40 mm thick immediately anterior to the knee, which may represent subcutaneous edema or developing cellulitis, with no evidence of right knee joint effusion (Fig 3A and $\mathrm{B})$. 


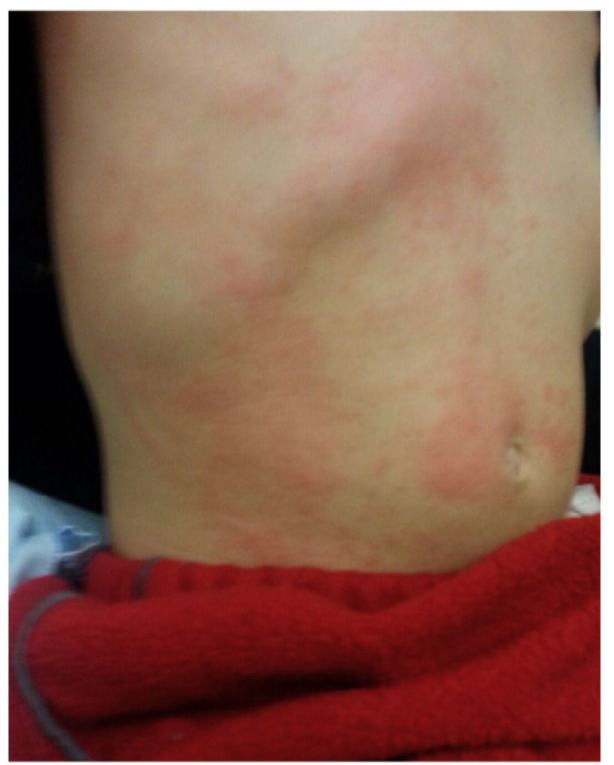

Fig 2. Abdomen presentation at hospital 1 hour after initial diagnosis.

Immediately after receiving the radiograph report, the patient was admitted to the pediatric unit and treated with $115 \mathrm{mg}$ of palmitate liquid, clindamycin (Cleocin oral) $15 \mathrm{mg}$, and amoxicillin $200 \mathrm{mg}$ every 8 hours. These are the conventional guideline medications used for severe skin infections when considering the possibility of NF or MRSA. ${ }^{10,15-24}$ The rapid spreading of the patient's rash showed pathognomonic markings similar to the presentation of NF, which has a higher potential to induce shock, especially in a young child.

The treatment was tolerated well. The erythema over the patient's abdomen, torso, and bilateral knees resolved with no evidence of dermatological deterioration (Fig 4A and B). The child was released from the hospital after 3 days of treatment and was directed to discontinue amoxicillin and continue with clindamycin oral $15 \mathrm{mg}$ for the following 8 days.

A follow-up appointment with the patient's pediatrician was 6 days post-hospital release. At this time, colitis, an adverse effect of clindamycin, was taken into consideration, and the medication was changed to amoxicillin $200 \mathrm{mg}$ every 8 hours for 10 days. Reoccurrence of the infection was noted, and treatment of clindamycin was reinstated. Upon completion of this round of treatment, a follow-up appointment was indicated. Afterward, the patient was instructed to continue with the regimen of clindamycin for an additional 2 weeks before there was no sign of reissued infections or complications. The parent of the patient provided consent for the publication of this case report.
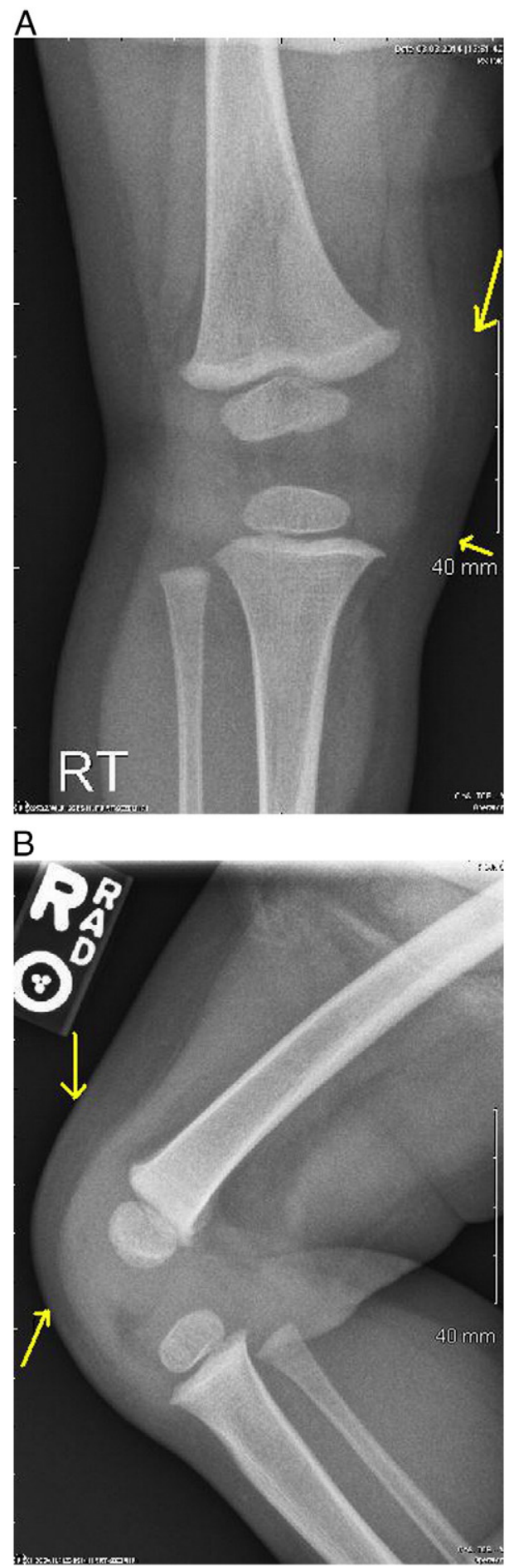

Fig 3. A, Anteroposterior projection of patient's right knee with $40 \mathrm{~mm}$ of thickening anterior to knee. B, Lateral projection of patient's right knee.

\section{Discussion}

Cellulitis is a skin infection of the subcutaneous tissues that is clinically diagnosed based on the 


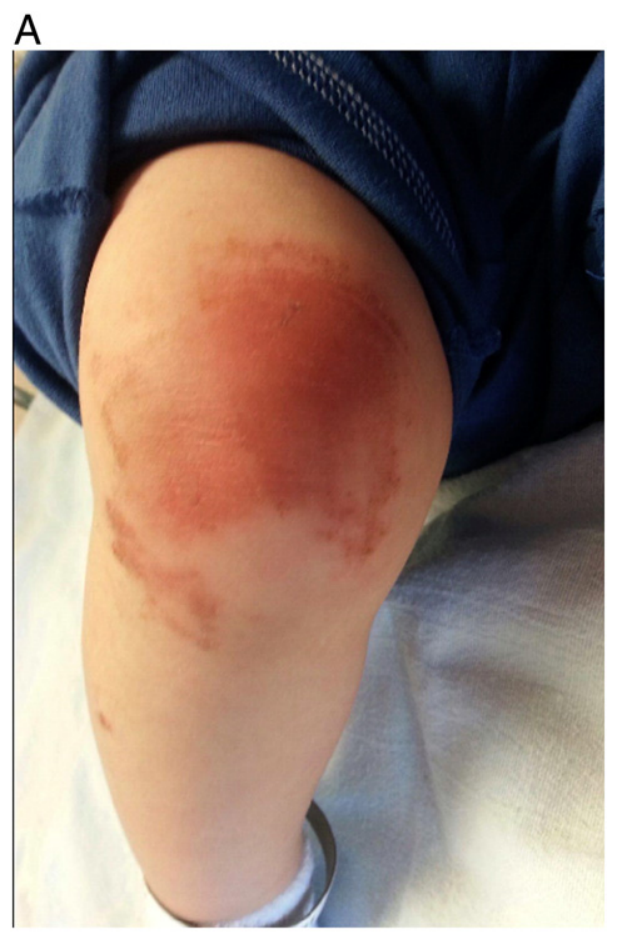

B

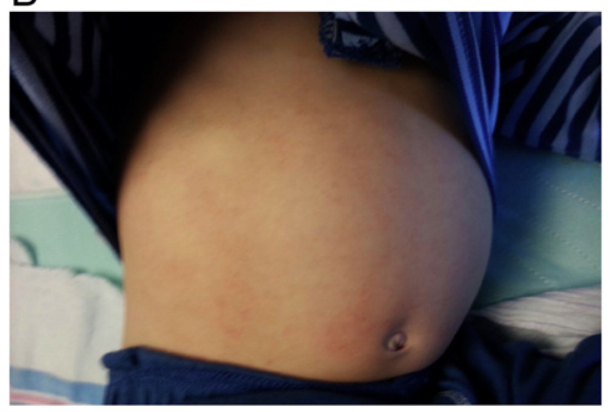

Fig 4. A, Patient's right knee on day of hospital discharge. B, Patient's abdomen on day of hospital discharge.

presentation of a nonpurulent erythematic rash with striations and irregular margins, swelling, and local tenderness, ${ }^{1-4,11,14,17,18,25}$ as seen in this case. It also has the potential to spread rapidly to various regions of the body adjacent to the initial dermatologic outbreak. An infection that spreads through the fascia and skin could have detrimental consequences for a 16-month-old child. Because the rash had changed in a matter of hours, the possibility of toxic shock was not to be dismissed or taken lightly. However, toxic shock is more frequently seen in NF. Clindamycin is considered the most effective agent against group A streptococci and is frequently used in the treatment of severe infections such as NF to prevent streptococcal toxic shock syndrome. ${ }^{7-10,15-21,26-29}$
Methicillin-resistant $S$ aureus has been talked about since the mid-20th century, when it was first discovered in humans. In the United States, about 3.2\% of all ED visits between 2007 and 2010 were related to skin infection, and $68 \%$ were treated with anti-MRSA agent antibiotics. $7,9,10,19,23-25,27,28,30$ About $10 \%$ of cellulitis cases are reported to be related to invasive MRSA 4. Because of the increased number of abscesses that turn into NF, cellulitis, and/or MRSA, hospitals are currently taking a more aggressive approach in treatment. According to the literature, the first line of treatment for an infection depends on the regional risk for each condition. The increased number of cases in each region will therefore determine the treatment of choice that will be available for the physician to provide. ${ }^{11,14,16-18,25}$

To identify the cause of the infection, complete blood count and blood cultures are the primary laboratory tests. Cellulitis is frequently due to staphylococcal or streptococcal species infections. It is difficult to obtain a positive cell culture in these 2 species because of the nonpurulent characteristics of each organism. In this case, a blood culture was not part of the diagnostic test ordered during initial examination at the ED.

The rapidly spreading presentation of cellulitis in this case revealed markings that are similar to the presentation of NF, which has a higher potential to induce shock, especially in a 16-month-old child. Most skin infections will initially have a similar presentation. It is very important to consider the different possibilities in diagnosis and to pay close attention to the symptomatology of every case.

The appearance of cellulitis in this particular case is considered to be extremely rare given the region in the body, age, and medical history. Disposition of cellulitis in a patient of this age is most commonly found in the head region in approximately $71 \%$ of cases and occurs in the extremities in approximately $26 \%$ of cases. It is even more uncommon in the lower extremities, as knee presentations only account for approximately $6.5 \%$ of the patients younger than 18 years. Cellulitis in the lower extremities is most common in the geriatric population. ${ }^{6,10-14,29,31,32}$

\section{Limitations}

The limitations of this report include that it is a single case report. This patient presentation is not typical for a chiropractic patient, as it is not a musculoskeletal complaint. There is limited chiropractic literature on the topic, considering the age of the patient and anatomical distribution of the case presentation. 


\section{Conclusion}

Cellulitis of the knee is not a common site for a 16-month-old child. Most initial presentations could be dismissed as an allergic reaction, which would delay diagnosis and treatment in this case. Closer attention needs to be paid to the progression of any skin infection even when there is no history of trauma or insect bites, or if a compromised medical history is present. Fast recognition and referral to the $\mathrm{ED}$, together with patient or guardian education and immediate care, are crucial to improve the prognosis of any patient with nonconventional dermatologic signs and symptoms.

\section{Funding Sources and Conflicts of Interest}

No funding sources or conflicts of interest were reported for this study. This case report is submitted as partial fulfillment of the requirements for the degree of Master of Science in Advanced Clinical Practice at the Lincoln College of Post-professional, Graduate, and Continuing Education at the National University of Health Sciences.

\section{References}

1. Gomes de Vasconcellos A, Leal R, Silvany-Neto A, NascimentoCarvalho C. Oxacillin or cefalotin treatment of hospitalized children with cellulitis. Jpn J Infect Dis 2012;65:7-12.

2. Herzberger EH, Aviner S, Cherniavsky E. Post traumatic fat necrosis presented as cellulitis of the leg. Case Rep Pediatr 2012;2012:672397.

3. Wathen D, Halloran DR. Blood culture associations in children with a diagnosis of cellulitis in the era of methicillin-resistant Staphylococcus aureus. Hosp Pediatr 2013;3(2):103-7.

4. Mason JM, Thomas KS, Crook AM, et al. Prophylactic antibiotics to prevent cellulitis of the leg: economic analysis of the PATCH I \& II Trials. PLoS One 2014;9(2):e82694.

5. Larkin-Thier SM, Barber VA, Pain Harvey, Livdans-Forret AB. Community-acquired methicillin-resistant Staphylococcus aureus: a potential diagnosis for a 16-year-old athlete with knee pain. J Chiropr Med 2010;9:32-7.

6. Navinan MR, Yudhishdran J, Kandeepan T, Kulatunga A. Necrotizing fasciitis - a diagnostic dilemma: two case reports. J Med Case Rep 2014;8:229.

7. Nguyen L, Rowland K. Low-dose penicillin for recurrent cellulitis. J Fam Pract 2014;63(1):E10-2.

8. Lee CY, Tsai HC, Kunin CM, Lee SS, Chen YS. Clinical and microbiological characteristics of purulent and non-purulent cellulitis in hospitalized Taiwanese adults in the era of community-associated methicillin-resistant Staphylococcus au- reus. BMC Infect Dis 2015;15(1):311, http://dx.doi.org/ 10.1186/s12879-015-1064-z [PMID: 26242240].

9. Lai-Kwon J, Weiland TJ, Chong AH, Jelinek GA. Which dermatological conditions present to an emergency department in Australia. Emerg Med Int 2014;2014:463026.

10. Pallin DJ, Camargo CA, Schuur JD. Skin infections and antibiotic stewardship: analysis of emergency department prescribing practices, 2007-2010. West J Emerg Med 2014; 15(3):282-9.

11. Krishnan N, Ramamoorthy N, Panchanathan S, Balasundaram JS. Infantile maxillary sinus osteomyelitis mimicking orbital cellulitis. J Glob Infect Dis 2014;6(3):125-7, http://dx.doi.org/ 10.4103/0974-777X.138511 [PMID: 25191055].

12. Smith JM, Bratton EM, DeWitt P, Davies BW, Hink EM, Durairaj VD. Predicting the need for surgical intervention in pediatric orbital cellulitis. Am J Ophthalmol 2014;158(2): 387-394.e1, http://dx.doi.org/10.1016/j.ajo.2014.04.022 [Epub 2014 May 1. PMID: 24794092].

13. Kara A, Ozsurekci Y, Tekcicek M, et al. Length of hospital stay and management of facial cellulitis of odontogenic origin in children. Pediatr Dent 2014;36(1):18E-22E [PMID: 24717702].

14. Larru B, Gerber JS. Cutaneous bacterial infections caused by Staphylococcus aureus and Streptococcus pyogenes in infants and children. Pediatr Clin North Am 2014;61(2):457-78, http://dx.doi.org/10.1016/j.pc1.2013.12.004 [Epub 2014 Jan 23. Review. PMID: 24636656].

15. Olafsdottir LB, Erlendsodottir H, Melo-Cristino J, et al. Invasive infections due to Streptococcus pyogenes: seasonal variation of severity and clinical characteristics, Iceland, 1975 to 2012. Euro Surveill 2014;19(17):5-143.

16. Teran CG, Sura S, Thant Lin TM, et al. Current role of community-acquired Methicillin-resistant Staphylococcus aureus among children with skin and soft tissue infections. Pediatr Rep 2012;4(1):e5.

17. Acuña M, Benadof D, Jadue C, et al. Community associatedmethicillin-resistant Staphylococcus aureus (SAMR-AC): communication of the first four pediatric cases in the Roberto del Rio Children's Hospital. Rev Chilena Infectol 2015;32(3): 350-6, http://dx.doi.org/10.4067/S0716-10182015000400016 [Spanish. PMID: 26230445].

18. Alayed KA, Tan C, Daneman N. Red flags for necrotizing fasciitis: a case control study. Int J Infect Dis 2015;36:15-20, http://dx.doi.org/10.1016/j.ijid.2015.04.021 [Epub 2015 May 11. PMID: 25975653].

19. Gujral S, Fonseca Huges JM, Wiberg A. Necrotizing fasciitis. Eplasty 2014;14:ic15.

20. Green BN, Johnson CD, Egan JT, Rosenthal M, Griffith EA, Evans MW. Methicillin-resistant Staphylococcus aureus: an overview for manual therapists. J Chiropr Med 2012;11:64-76.

21. Thomas S, Omole F, Patel VG, Nichols ML. "The clock is ticking": the timely management of a painful skin rash in a seventy-year-old woman. Case Rep Med 2014;2014:641058.

22. Park JS, Lim CW, Park T, Cho JM, Seo JH, Youn HS. Suppurative Meckel diverticulum in a 3-year-old girl presenting with periumbilical cellulitis. Pediatr Gastroenterol Hepatol Nutr 2015;18(1):66-70, http://dx.doi.org/10.5223/ pghn.2015.18.1.66 [Epub 2015 Mar 30. PMID: 25866736].

23. van Bijnen EM, Paget WJ, den Heijer CD, et al. Primary care treatment guidelines for skin infections in Europe: congruence with antimicrobial resistance found in commensal 
Staphylococcus aureus in the community. BMC Fam Pract 2014;15:175, http://dx.doi.org/10.1186/s12875-014-0175-8 [PMID: 25413920].

24. Moore SJ, O'Leary ST, Caldwell B, et al. Clinical characteristics and antibiotic utilization in pediatric patients hospitalized with acute bacterial skin and skin structure infection. Pediatr Infect Dis J 2014;33(8):825-8, http://dx.doi.org/10.1097/ INF.0000000000000304 [PMID: 25222301].

25. Nguyen T, Haberland CA, Hernandez-Boussard T. Pediatric patient and hospital characteristics associated with treatment of peritonsillar abscess and peritonsillar cellulitis. Clin Pediatr (Phila) $2015 ; 54: 1240-6$.

26. Quirke M, Boland F, Fahey T, et al. Prevalence and predictors of initial oral antibiotic treatment failure in adult emergency department patients with cellulitis: a pilot study. BMJ Open 2015;5(6):e008150, http://dx.doi.org/10.1136/bmjopen-2015008150 [PMID: 26112223].

27. Claeys KC, Lagnf AM, Patel TB, Jacob MG, Davis SL, Rybak MJ. Acute bacterial skin and skin structure infections treated with intravenous antibiotics in the emergency department or observational unit: experience at the Detroit Medical Center. Infect Dis Ther 2015;4(2):173-86, http:// dx.doi.org/10.1007/s40121-015-0069-7 [Epub 2015 Jun 9. PMID: 26055392].
28. Durkin MJ, Corey GR. New developments in the management of severe skin and deep skin structure infections-focus on tedizolid. Ther Clin Risk Manag 2015;11:857-62, http://dx.doi.org/10.2147/TCRM.S64553 [eCollection 2015. Review. PMID: 26045667].

29. Pesola AK, Sihvonen R, Lindholm L, Pätäri-Sampo A. Clindamycin resistant emm33 Streptococcus pyogenes emerged among invasive infections in Helsinki metropolitan area, Finland, 2012 to 2013. Euro Surveill 2015;20(18) [pii: 21117. PMID: 25990232].

30. Vaziri K, Pershing S, Albini TA, Moshfeghi DM, Moshfeghi AA. Risk factors predictive of endogenous endophthalmitis among hospitalized patients with hematogenous infections in the United States. Am J Ophthalmol 2015;159(3):498-504, http://dx.doi.org/10.1016/j.ajo.2014.11.032 [Epub 2014 Dec 6. PMID: 25486541].

31. Miller LG, Eisenberg DF, Liu H, et al. Incidence of skin and soft tissue infections in ambulatory and inpatient settings, 2005-2010. BMC Infect Dis 2015;15:362, http://dx.doi.org/ 10.1186/s12879-015-1071-0 [PMID: 26293161].

32. Baskin SM, Abboud C, Chen W, Tolchin E, Kelly RW, Aballay AM. Subcutaneous injection of Percocet: a case of severe soft tissue loss. Wounds 2015;27(7):174-9 [PMID: 26192735]. 